\title{
Health, financial stresses, and life satisfaction affecting late-life depression among older adults: a nationwide, longitudinal survey in Taiwan
}

\author{
Bee-Horng Lue ${ }^{\mathrm{a}}$, Liang-Ju Chen ${ }^{\mathrm{b}}$, Shwu-Chong $\mathrm{Wu}^{\mathrm{b}, *}$ \\ ${ }^{a}$ Department of Family Medicine, National Taiwan University Hospital and College of Medicine, National Taiwan University, No. 7 Chung-Shan South Road, Taipei, Taiwan 100 \\ ${ }^{b}$ Institute of Health Policy and Management, College of Public Health, National Taiwan University. 6F, No. 17 Xu-Zhou Rd., Taipei, Taiwan 100
}

\section{A R T I C L E I N F O}

\section{Keywords:}

Depression

Stress

Life satisfaction of elderly

Longitudinal survey

Taiwan

\begin{abstract}
A B S T R A C T
The purpose of this study was to determine the incidence of depression in late life and to explore associated risk factors among Taiwanese elderly. The analyses were based on nationally representative data from the Survey of Health and Living Status of the Elderly in 1999 and 2003. A total of 1,487 respondents aged 65 years and older who completed the 10 -item Center for Epidemiological Survey Depression (CES-D) scale in these two surveys and without depression in 1999 were included in the final analyses. Depression was defined as a CES-D score equal to or greater than 10 . The independent variables included sociodemographic characteristics, occurrence of new diseases, social support, perceived health and financial stresses, life satisfaction, and functional condition. The incidence rate of depression over 4 years was $19.7 \%$. Multivariate regression analyses revealed that women who perceived greater health or financial stress and who had greater life dissatisfaction or worsened functional condition were more likely to suffer depression. These findings imply that healthcare programs for older adults should include cognitive and behavioral interventions in order to prevent the development of depression in late life.
\end{abstract}

(c) 2010 Elsevier Ireland Ltd. All rights reserved.

\section{Introduction}

Depression, which is prevalent in older adults, is associated with serious consequences, such as increased risk of morbidity, increased risk of suicide, decreased physical, cognitive, and social functioning, and adversely affects the outcome of comorbid problems, all of which are, in turn, associated with increased mortality and healthservice utilization (Cuijpers and Smit, 2002; Blazer, 2003).

The prevalence of depressive symptoms among communitydwelling older adults ranged from $8 \%$ to $20 \%$ in studies done in the United States and internationally (Blazer et al., 1988, 1991; Beekman et al., 1995), while in Taiwan's community studies it was $13-26 \%$ (Wu and Chang, 1997; Chiu et al., 2005). Therefore, investigating this critical public-health issue in Taiwan, where adults 65 years and older account for $10.53 \%$ of a total population of 23 million people, is of great urgency (Council for Economic Planning and Development, 2008).

The etiology of depression in older adults has been suggested to be an interaction between certain vulnerabilities, including genetic factors, cognitive diathesis, age-associated neurobiological changes, and the stressful events that occur more frequently in late life (Fiske et al., 2009). As older adults age, they inevitably have to face their failing physical health or diseases. In addition to actively

\footnotetext{
* Corresponding author.

Tel.: +(886-2)-3366-8049; fax: +(886-2)-2311-8674.

E-mail address: suewu@ntu.edu.tw (S-C. Wu).
}

managing their physical illnesses, understanding and mastering the psychosocial risk factors might be an effective way to prevent the development of depression in later life.

Among psychosocial factors, neurotic personality (Kendler et al., 2006), ruminative and avoidant coping styles (Garnefski and Kraaij, 2006), stressful events in late life, such as deterioration of financial status (Fiske et al., 2003), a new physical illness, or disability and loneliness (Nolen-Hoeksema and Ahrens, 2002), as well as inadequate social support (Krause and Liang, 1993; Brummett et al., 2000; Chi and Chou, 2001), have all been shown to be associated with depression. However, most of these studies were cross-sectional, so the causal relationship between depression and these risk factors could not be determined.

The present study aimed to assess the incidence of depression in late life and to explore associated risk factors from a sample representative of community-dwelling older adults who were followed-up longitudinally in Taiwan.

\section{Subjects and methods}

\subsection{Sample}

The data of this study were derived from the Survey of Health and Living Status of the Elderly in Taiwan, a representative nationwide longitudinal survey starting in 1989 and followed-up in 1993, 1996, 1999, and 2003. The sampling involved a three-stage probability sampling technique, and township was used as the primary sam- 
pling unit. The detailed research design and sampling strategy have been reported elsewhere (Glei et al., 2005; Zimmer et al., 2005).

In 1999, there were 2,890 respondents aged 65 years and over; of these, 2,154 completed the follow-up survey by household interview in 2003. Reasons for those who did not complete the survey included death (87.9\%), incomplete interview (8.2\%), and lost to follow-up (3.9\%). Of the 2,154 respondents, the 2,045 who completed the CES-D scale both in 1999 and in 2003 were enrolled in our study. A further 177 respondents were excluded because the survey was completed by proxy in 2003 . Thus, 1,868 respondents matched the criteria, and 1,487 respondents without depression in 1999 were included in the final analyses.

\subsection{Measurements}

In this study, depression, the dependent variable, was measured using the 10-item CES-D scale. The 10-item CES-D is a selfreported scale and is the short form of the original 20-item CES-D constructed by Radloff in 1977 (Radloff, 1977); however, the 10-item CES-D preserves the same sensitivity and specificity as the 20-item scale (Shrout and Yager, 1989; Kohout et al., 1993). Furthermore, the CES-D scale has performed well in cross-cultural and older population studies, including the elderly Chinese (Krause and Liang, 1992; McCallum et al., 1995; Boey, 1999; Irwin et al., 1999; Ofstedal et al., 1999). The range of scores in the 10 -item CES-D is from 0 to 30 , where a score equal to or higher than 10 is defined as depression, and less than 10 indicates no depression (Andresen et al., 1994). Cronbach's $\alpha$ reliability coefficients for the 10-item CES-D in the 1999 and 2003 surveys were 0.84 and 0.86 , respectively (Seplaki et al., 2006).

Respondent's socio-demographic characteristics, occurrence of new diseases, social support, perceived health and financial stresses, life satisfaction, and change in functional condition were included as independent variables.

Socio-demographic variables included in the study were age, gender, marital status, ethnicity, and education. Marital status was assessed by its change over these four years, and grouped into three categories as: single (including divorced, never married, and separated), widowed after 1999, and with spouse. Ethnicity was divided into three categories: Fukien, Mainlanders, and Hakka and others. Education was grouped into three levels: no formal education, elementary, and junior high school and over.

The occurrence of new diseases was assessed based on having any one of the following diseases in 2003: hypertension, heart disease, stroke, diabetes, kidney diseases, cancer, lung diseases, arthritis or rheumatism, gastrointestinal diseases, liver and gall bladder diseases, and gout. Respondents were grouped into two categories: those having and those not having these diseases.

Social support includes various types of support received from relatives or friends (Cobb, 1976; Cohen and Syme, 1985). In this study, emotional and instrumental supports were assessed by selfreport (Berkman et al., 1992). Emotional support included concern, caring, and trust, and instrumental support encompassed receiving help in the form of money, needs of daily life (such as food, clothes, or goods), housework chores, and transportation for going out. These variables were measured using the five-point Likert scale, with higher scores indicating more support. The change in emotional and instrumental social support was measured by the score difference between 1999 and 2003, and the results were regrouped into three categories: worse, no change, and improved.

Perceived health and financial stresses were also measured as four degrees, which were rated from no perceived stress to a frequently feeling stressed. According to the different degree of perceived stress between 1999 and 2003, the respondents were categorized as worse, no change, and improved. Life satisfaction was measured using the Life Satisfaction Index-A (LSI-A) that was constructed by Neugarten in 1961 for evaluating life satisfaction in the past, present, and future. The LSI-A comprises 10 items, and the total score ranges from 0 to 10 , with higher scores indicating more life satisfaction. The Cronbach's $\alpha$ reliability coefficient was 0.84 . The change level in life satisfaction was also measured by the score difference between 1999 and 2003, and the results were regrouped into three categories: worse, no change, and improved.

Functional condition was measured by the activities of daily living (ADL) (Katz et al., 1963) and instrumental activities of daily living (IADL) (Lawton and Brody, 1969). The ADL concerns eating, dressing, transferring, bathing, walking indoors, and using the toilet. Respondents were asked if they were able to perform ADL functions by themselves without other's assistance or special equipment. IADL included making phone calls, doing light chores, shopping, and managing personal finances Functional condition was divided into three levels: no disability, only IADL disability, and ADL disability. The difference in respondents' functional condition between 1999 and 2003 was identified and categorized as worse or not worse.

\subsection{Statistical analyses}

Descriptive statistics, bivariate comparisons, and multivariate modeling were conducted using SPSS 15.0 software (Chicago, IL, USA), and the results were considered significant at $\mathrm{p}<0.05 . \chi^{2}$-test was used to examine the significance of differences. Multivariate logistic regression was applied to analyze the factors affecting the occurrence of depression in 2003.

\section{Results}

In 1999, of the 1,868 respondents, 381 had depression. The prevalence rate was 20.4\%. From 1999 to 2003, 293 of 1,487 respondents developed depression: an incidence rate of $19.7 \%$.

The characteristics of the study sample are shown in Table 1. Of 1,487 subjects without depression in $1999,58.3 \%$ were male, and their mean age was 72.8 years. Overall, more than a third of the respondents (35.5\%) did not have a formal education, and about one quarter (25.4\%) had a junior high school diploma and higher. Regarding change in marital status, $60.1 \%$ were living with a spouse, but $8.7 \%$ were widowed after 1999 . Only $6.5 \%$ of respondents had new diseases. Compared with 1999, the percentages with worse perceived health and financial stress were $20.7 \%$ and $15.3 \%$, respectively. The proportion of respondents with improved instrumental social support was $39.7 \%$, compared to $22.1 \%$ for whom support worsened. In addition, more than half (54.9\%) of the respondents did not report a change in emotional support, with $23.8 \%$ stating worse emotional support and $21.3 \%$ with better emotional support. Interestingly, a steeper fluctuation in the percentage of change of life satisfaction was noted, as it exceeded the values of perceived stress and social support; $42.8 \%$ were worse and $37.5 \%$ were better. Change in functional condition from 2003 was reported to be worse in $17.1 \%$ of cases.

In Table 2, the results of bivariate analyses show that gender, education, change in marital status, ethnicity, occurrence of new diseases, change in perceived stresses, life satisfaction, and functional condition were significantly associated with depression in 2003.

Compared to male respondents, the prevalence of depression was higher among females. Those with a lower level of education had a higher rate of depression; the percentage for those with no formal education was more than one quarter $(25.9 \%)$, which was down to $17.0 \%$ for elementary, and $15.1 \%$ for junior high and over. Persons with a spouse had a lower percentage (16.5\%) of depression than others (26.2\% for widowed after 1999 and 24.0\% for singles). With respect to ethnicity, more Fukien (21.7\%) had depression than Mainlanders, or Hakka and others. Among respondents with new diseases, $27.8 \%$ had depression, which was significantly higher than 
Table 1

Characteristics of the sample $(n=1,487)$

\begin{tabular}{|c|c|c|c|}
\hline Variable & Subgroups & $\mathrm{n}$ & $(\%)$ \\
\hline \multirow[t]{2}{*}{ Sex } & Male & 867 & $(58.3)$ \\
\hline & Female & 620 & $(41.7)$ \\
\hline \multirow[t]{3}{*}{ Age (years) } & $65-69$ & 371 & $(24.9)$ \\
\hline & $70-74$ & 629 & $(42.3)$ \\
\hline & $75+$ & 487 & $(32.8)$ \\
\hline \multirow[t]{3}{*}{ Education } & No formal education & 528 & $(35.5)$ \\
\hline & Elementary school & 581 & $(39.1)$ \\
\hline & Junior high school and higher & 378 & $(25.4)$ \\
\hline \multirow[t]{3}{*}{ Marital status } & With spouse & 893 & $(60.1)$ \\
\hline & Widowed after 1999 & 130 & $(8.7)$ \\
\hline & Single & 463 & $(31.1)$ \\
\hline \multirow[t]{3}{*}{ Ethnicity } & Fukien & 869 & $(58.4)$ \\
\hline & Mainlander & 364 & $(24.5)$ \\
\hline & Hakka and others & 246 & $(16.5)$ \\
\hline \multirow[t]{2}{*}{ Occurrence of new diseases } & No & 1,390 & $(93.5)$ \\
\hline & Yes & 97 & $(6.5)$ \\
\hline \multirow[t]{3}{*}{ Perceived health stress } & No change & 935 & $(62.9)$ \\
\hline & Worse & 308 & $(20.7)$ \\
\hline & Improved & 244 & $(16.4)$ \\
\hline \multirow[t]{3}{*}{ Perceived financial stress } & No change & 1,066 & $(71.7)$ \\
\hline & Worse & 227 & $(15.3)$ \\
\hline & Improved & 194 & $(13.0)$ \\
\hline \multirow[t]{3}{*}{ Instrumental social support } & No change & 568 & $(38.2)$ \\
\hline & Worse & 328 & $(22.1)$ \\
\hline & Improved & 591 & (39.7) \\
\hline \multirow[t]{3}{*}{ Emotional social support } & No change & 817 & $(54.9)$ \\
\hline & Worse & 354 & $(23.8)$ \\
\hline & Improved & 316 & $(21.3)$ \\
\hline \multirow[t]{3}{*}{ Life satisfaction } & No change & 293 & (19.7) \\
\hline & Worse & 636 & $(42.8)$ \\
\hline & Improved & 558 & $(37.5)$ \\
\hline \multirow[t]{2}{*}{ Functional condition } & Not worse & 1,232 & $(82.9)$ \\
\hline & Worse & 255 & $(17.1)$ \\
\hline
\end{tabular}

among those who did not have new diseases (19.1\%). A greater proportion of depression was found in respondents perceiving various stresses. For health stress, 39.9\% of respondents who felt more stressed had depression, compared to $18.4 \%$ of those who felt less stressed or $13.4 \%$ of those who felt no change. For financial stress, $37.9 \%$ of respondents who perceived more stress had depression. Respondents with worse life satisfaction had a higher rate of depression (27.4\%), compared to $15.4 \%$ of those with no change, or $13.3 \%$ with improved life satisfaction. The rate of depression was higher in respondents whose functional condition worsened.

The results of multivariate logistic regression are presented in Table 3. After controlling for other important variables in the model, sex, change of perceived stresses, life satisfaction, and functional condition had significant effects on depression in 2003.

Compared to males, female respondents were more likely to have depression in 2003 ( $\mathrm{OR}=1.577,95 \% \mathrm{CI}=1.135-2.191)$. Changes in perceived stresses were significantly associated with having depression. Compared to those with no change in perceived stresses, respondents who perceived more health stress were more likely to be depressed ( $\mathrm{OR}=3.061,95 \% \mathrm{CI}=2.212-4.236)$. The odds ratio of more perceived financial stress was $2.018(95 \% \mathrm{CI}=$ 1.411-2.885). Furthermore, respondents with worse life satisfaction in 2003 were more likely to have depression, with an odds ratio of
Table 2

Bivariate analyses of the association of depression (D) in 2003 and other characteristics, $\mathrm{n}$ or $\mathrm{n}(\%)$

\begin{tabular}{|c|c|c|c|c|c|}
\hline Variable & Subgroup & $\begin{array}{l}\text { Total, } \\
\mathrm{n}= \\
1,487\end{array}$ & $\begin{array}{l}-\mathrm{D} \\
\mathrm{n}=1,194\end{array}$ & $\begin{array}{l}+D \\
n=293\end{array}$ & $\mathrm{p}=$ \\
\hline Sex & $\begin{array}{l}\text { Male } \\
\text { Female }\end{array}$ & $\begin{array}{l}867 \\
620\end{array}$ & $\begin{array}{l}736(84.9) \\
458(73.9)\end{array}$ & $\begin{array}{l}131(15.1) \\
162(26.1)\end{array}$ & $<0.001$ \\
\hline Age (years) & $\begin{array}{l}65-69 \\
70-74 \\
75+\end{array}$ & $\begin{array}{l}371 \\
629 \\
487\end{array}$ & $\begin{array}{l}297(80.1) \\
517(82.2) \\
380(78.0)\end{array}$ & $\begin{array}{l}74(19.9) \\
112(17.8) \\
107(22.0)\end{array}$ & 0.065 \\
\hline Education & $\begin{array}{l}\text { No formal edu. } \\
\text { Elementary } \\
\text { Junior high and + }\end{array}$ & $\begin{array}{l}528 \\
581 \\
378\end{array}$ & $\begin{array}{l}391(74.1) \\
482(83.0) \\
321(84.9)\end{array}$ & $\begin{array}{l}137(25.9) \\
99(17.0) \\
57(15.1)\end{array}$ & $<0.001$ \\
\hline Marital status & $\begin{array}{l}\text { With spouse } \\
\text { Widowed after } 1999 \\
\text { Single }\end{array}$ & $\begin{array}{l}893 \\
130 \\
463\end{array}$ & $\begin{array}{l}746(83.5) \\
96(73.8) \\
352(76.0)\end{array}$ & $\begin{array}{l}147(16.5) \\
34(26.2) \\
111(24.0)\end{array}$ & $<0.001$ \\
\hline Ethnicity & $\begin{array}{l}\text { Fukien } \\
\text { Mainlander } \\
\text { Hakka + others }\end{array}$ & $\begin{array}{l}869 \\
364 \\
246\end{array}$ & $\begin{array}{l}680(78.3) \\
306(84.1) \\
203(82.5)\end{array}$ & $\begin{array}{l}189(21.7) \\
58(15.9) \\
43(17.5)\end{array}$ & 0.042 \\
\hline $\begin{array}{l}\text { Occurrence of new } \\
\text { diseases }\end{array}$ & $\begin{array}{l}\text { No } \\
\text { Yes }\end{array}$ & $\begin{array}{l}1,390 \\
97\end{array}$ & $\begin{array}{l}1,124(80.9) \\
70(72.2)\end{array}$ & $\begin{array}{l}266(19.1) \\
27(27.8)\end{array}$ & 0.037 \\
\hline Perc. health stress & $\begin{array}{l}\text { No change } \\
\text { Worse } \\
\text { Improved }\end{array}$ & $\begin{array}{l}935 \\
308 \\
244\end{array}$ & $\begin{array}{l}810(86.6) \\
185(60.1) \\
199(81.6)\end{array}$ & $\begin{array}{l}125(13.4) \\
123(39.9) \\
45(18.4)\end{array}$ & $<0.001$ \\
\hline Perc. financ. stress & $\begin{array}{l}\text { No change } \\
\text { Worse } \\
\text { Improved }\end{array}$ & $\begin{array}{l}1,066 \\
227 \\
194\end{array}$ & $\begin{array}{l}893(83.8) \\
141(62.1) \\
160(82.5)\end{array}$ & $\begin{array}{l}173(16.2) \\
86(37.9) \\
34(17.5)\end{array}$ & $<0.001$ \\
\hline $\begin{array}{l}\text { Instrumental social } \\
\text { support }\end{array}$ & $\begin{array}{l}\text { No change } \\
\text { Worse } \\
\text { Improved }\end{array}$ & $\begin{array}{l}568 \\
328 \\
591\end{array}$ & $\begin{array}{l}466(82.0) \\
258(78.7) \\
470(79.5)\end{array}$ & $\begin{array}{l}102(18.0) \\
70(21.3) \\
121(20.5)\end{array}$ & 0.392 \\
\hline $\begin{array}{l}\text { Emotional social } \\
\text { support }\end{array}$ & $\begin{array}{l}\text { No change } \\
\text { Worse } \\
\text { Improved }\end{array}$ & $\begin{array}{l}817 \\
354 \\
316\end{array}$ & $\begin{array}{l}664(81.3) \\
281(79.4) \\
249(78.8)\end{array}$ & $\begin{array}{l}153(18.7) \\
73(20.6) \\
67(21.2)\end{array}$ & 0.568 \\
\hline Life satisfaction & $\begin{array}{l}\text { No change } \\
\text { Worse } \\
\text { Improved }\end{array}$ & $\begin{array}{l}293 \\
636 \\
558\end{array}$ & $\begin{array}{l}248(84.6) \\
462(72.6) \\
484(86.7)\end{array}$ & $\begin{array}{l}45(15.4) \\
174(27.4) \\
74(13.3)\end{array}$ & $<0.001$ \\
\hline Functional condition & $\begin{array}{l}\text { Not worse } \\
\text { Worse }\end{array}$ & $\begin{array}{l}1,232 \\
255\end{array}$ & $\begin{array}{l}1,038(84.3) \\
156(61.2)\end{array}$ & $\begin{array}{l}\text { 194(15.7) } \\
99(38.8)\end{array}$ & $<0.001$ \\
\hline
\end{tabular}

1.917 (95\% CI $=1.292-2.844)$. Thus, changing functional condition was also a significant variable for depression; the effect was evident among respondents with worse function $(\mathrm{OR}=2.391,95 \% \mathrm{CI}=$ 1.717-3.328).

\section{Discussion}

The present study demonstrated that the prevalence of depression in a representative sample of community-dwelling older adults in Taiwan in 1999 was $20.4 \%$, which was similar to the results of previous studies (Wu and Chang, 1997; Chiu et al., 2005). The most noteworthy finding of this study is the incidence rate $(19.7 \%$ ) of depression in late life that could only be revealed by a longitudinal study. To the best of our knowledge, no other study focusing on this aspect has been conducted so far in Taiwan. This high incidence rate of depression among older adults highlights the challenge of healthcare professionals and governments in the era of global aging, as well as its profound implications on social, economic, and health policy.

From 1999 to 2003, only 6.5\% of respondents had new diseases, and $17.1 \%$ exhibited functional declines. This indicates that most of the respondents remained in fairly good physical condition. 
Table 3

Multivariate logistic regressions model for factors affecting depression in 2003 , $(n=1,487)$

\begin{tabular}{|c|c|c|c|c|c|}
\hline Variable & (Reference group) & B & OR & $(95 \% \mathrm{CI})$ & $\mathrm{p}$ \\
\hline \multirow[t]{2}{*}{ Sex } & (Male) & & & & \\
\hline & Female & 0.456 & 1.577 & $(1.135-2.191)$ & 0.007 \\
\hline \multirow[t]{3}{*}{ Age (years) } & $(65-69)$ & & & & \\
\hline & $70-74$ & -0.306 & 0.736 & $(0.514-1.056)$ & 0.096 \\
\hline & $75+$ & -0.199 & 0.819 & $(0.556-1.207)$ & 0.313 \\
\hline \multirow[t]{3}{*}{ Education } & (No formal education) & & & & \\
\hline & Elementary & -0.236 & 0.790 & $(0.561-1.111)$ & 0.176 \\
\hline & Junior high and + & -0.138 & 0.871 & $(0.569-1.334)$ & 0.526 \\
\hline \multirow[t]{3}{*}{ Marital status } & (With spouse) & & & & \\
\hline & Widowed after 1999 & 0.413 & 1.512 & $(0.926-2.468)$ & 0.098 \\
\hline & Single & 0.217 & 1.242 & $(0.895-1.725)$ & 0.195 \\
\hline \multirow[t]{3}{*}{ Ethnicity } & (Fukien) & & & & \\
\hline & Mainlander & 0.058 & 1.059 & $(0.712-1.576)$ & 0.776 \\
\hline & Hakka and others & -0.194 & 0.824 & $(0.552-1.230)$ & 0.343 \\
\hline \multirow[t]{2}{*}{ Occurrence of new diseases } & (No) & & & & \\
\hline & Yes & 0.288 & 1.334 & $(0.792-2.246)$ & 0.278 \\
\hline \multirow[t]{3}{*}{ Perceived health stress } & (No change) & & & & \\
\hline & Worse & 1.119 & 3.061 & $(2.212-4.236)$ & $<0.001$ \\
\hline & Improved & 0.325 & 1.384 & $(0.926-2.068)$ & 0.113 \\
\hline \multirow[t]{3}{*}{ Perceived financial stress } & (No change) & & & & \\
\hline & Worse & 0.702 & 2.018 & $(1.411-2.885)$ & $<0.001$ \\
\hline & Improved & 0.031 & 1.032 & $(0.662-1.609)$ & 0.890 \\
\hline \multirow[t]{3}{*}{ Instrumental social support } & (No change) & & & & \\
\hline & Worse & 0.129 & 1.137 & $(0.782-1.654)$ & 0.500 \\
\hline & Improved & 0.112 & 1.118 & $(0.810-1.543)$ & 0.497 \\
\hline \multirow[t]{3}{*}{ Emotional social support } & (No change) & & & & \\
\hline & Worse & -0.085 & 0.919 & $(0.648-1.304)$ & 0.636 \\
\hline & Improved & 0.230 & 1.258 & $(0.878-1.804)$ & 0.211 \\
\hline \multirow[t]{3}{*}{ Life satisfaction } & (No change) & & & & \\
\hline & Worse & 0.651 & 1.917 & $(1.292-2.844)$ & $<0.001$ \\
\hline & Improved & -0.114 & 0.892 & $(0.581-1.371)$ & 0.603 \\
\hline \multirow[t]{2}{*}{ Functional condition } & (Not worsened) & & & & \\
\hline & Worse & 0.872 & 2.391 & $(1.717-3.328)$ & $<0.001$ \\
\hline Constant & & -2.505 & 0.082 & & \\
\hline
\end{tabular}

However, since more respondents' perceived health and financial stresses, and nearly half of the respondents expressing worse life satisfaction, psychological issues should not be overlooked in older adults.

The main findings from bivariate analyses were that being female, having a low educational level, living alone, having new disease, perceiving more health or financial stress, worse life satisfaction, and worse functional condition were significantly associated with depression. These variables are consistent with those of previous studies (Blazer, 2003; Fiske et al., 2009). The present study also showed that age was not associated with depression. The reason for the higher frequency of depression among the older adults was explained by factors associated with aging, such as more physical disability, lower socioeconomic status, etc. (Blazer et al., 1988, 1991, Hybels et al., 2001), which were evident in our regression model.

No significant relationship was found between social support and depression. Since the present study was focused on the effect of change in social support for depression, we found that more respondents had better instrumental social support. Whether it had some role to play in the relationship needs further study. It has been claimed that the delivery of social support must be tailored to the individual's needs, because measures of received social support were shown to correlate both positively (Brummett et al., 2000) and negatively with the levels of depression (Krause and Markides, 1990; Bisschop et al., 2004a).

On multivariate regression analyses, perceptions of more health stress and worsened functional condition had a great impact on respondents' depression. The present findings might support the empirical evidence that late-life depression frequently occurs in the context of medical illness (Bisschop et al., 2004b; Chiu et al., 2005; Fiske et al., 2009), although we did not explore whether the stresses from health and the declining function were related to the medical diseases.

Furthermore, becoming more dissatisfied with life also, obviously, predicted late-life depression in our study. In past studies, life satisfaction was considered to be a subjective expression of quality of life, and psychological well-being and physical functioning were predictors of life satisfaction (Meléndez et al., 2009). One study conducted by Collins et al. (2008) in Taiwan using the same data set as our study demonstrated that life satisfaction was associated with the development of fewer mobility limitations and further supported the protective role of psychological well-being 
to physical decline in late life. Therefore, it is essential to have a thorough understanding of the diminishing life prospects of older adults in order to promote their mental health.

Deterioration of financial status is the most-frequently validated stressful life event experienced by older adults (Fiske et al., 2003). Older adults who have financial strain are more likely to experience depression (Mojtabai and Olfson, 2004). The present study also indicated that adults perceiving more financial stress were more likely to have depression.

Finally, some limitations of the study should be noted. Firstly, the incidence rate of depression might be underestimated because the CES-D is a self-reported scale. We excluded those participants who could not report by themselves. Secondly, no diagnostic interview to discriminate the categories of depression was performed. Thus, the risk factors contributing to different levels of depression could not be specified, though it has been suggested that major depression is more associated with long-standing vulnerability factors, while minor depression is more often a reaction to life stresses (Beekman et al., 1995). Nevertheless, from a public health perspective, the findings in our study provide information for designing a prevention program.

\section{Conclusions}

Perceived health and financial stresses, life dissatisfaction, and decreased function play vital roles in developing late-life depression among Taiwanese elderly persons. From the preventive point of view, the healthcare program for older adults should include cognitive and behavioral intervention, and active management of medical illness is essential.

\section{Conflict of interest statement}

None.

\section{Acknowledgements}

This study was supported financially by the National Science Council (NSC 95-2420-H002-014-KF). The data was provided by the Bureau of Health Promotion, Department of Health. The authors would like to thank these institutions for allowing us access to the data sets.

\section{References}

Andresen, E.M., Malmgren, J.A., Carter, W.B., Patrick, D.L., 1994. Screening for depression in well older adults: evaluation of a short form of the CES-D (Center for Epidemiologic Studies Depression Scale). Am. J. Prev. Med. 10, 77-84.

Beekman, A.T.F., Deeg, D.J.H., Van Tilburg, T., Smit, J.H., Hooijer, C., Van Tilburg, W., 1995. Major and minor depression in later life: a study of prevalence and risk factors. J. Affect. Disord. 36, 65-75

Berkman, L.F., Oxman, T., Seeman, T.E., 1992. Social networks and social support among the elderly: assessment issues. In: Wallace, R.B.A, Woolson, R.F. (Eds.), The Epidemiologic Study of The Elderly. New York: Oxford University Press. pp.: 196212.

Bisschop, M.I., Kriegsman, D.M.W., Beekman, A.T.F., Deeg, D.J.H., 2004a. Chronic diseases and depression: the modifying role of psychosocial resources. Soc. Sci. Med. 59, 721-733.

Bisschop, M.I., Didi, M.W.K., Dorly, J.H.D., Aartjan, T.F.B., Van Willem, T., 2004b. The longitudinal relation between chronic diseases and depression in older persons in the community: the Longitudinal Aging Study Amsterdam. J. Clin. Epidemiol. 57, $187-194$.

Blazer, D.G., 2003. Depression in late life: Review and commentary. J. Gerontol. A: Biol. Sci. Med. Sci. 58, M249-M265.

Blazer, D., Swartz, M., Woodbury, M., Manton, K.G., Hughes, D., George, L.K., 1988. Depressive symptoms and depressive diagnoses in a community population. Use of a new procedure for analysis of psychiatric classification. Arch. Gen. Psychiatry 45, 1078-1084.

Blazer, D., Burchett, B., Service, C., George, L.K., 1991. The association of age and depression among the elderly: An epidemiologic exploration. J. Gerontol. 46, M210-215.
Boey, K.W., 1999. Cross-validation of a short form of the CES-D in Chinese elderly. Int. J. Geriatr. Psychiatry. 14, 608-617.

Brummett, B.H., Barefoot, J.C., Siegler, I.C., Steffens, D.C., 2000. Relation of subjective and received social support to clinical and self-report assessments of depressive symptoms in an elderly population. J. Affect. Disord. 61, 41-50.

Chi, I., Chou, K.L., 2001. Social support and depression among elderly Chinese people in Hong Kong. Int. J. Aging Hum. Dev. 52, 231-252.

Chiu, H.-C., Chen, C.-M., Huang, C.-J., Mau, L.-W., 2005. Depressive symptoms, chronic medical conditions and functional status: a comparison of urban and rural elders in Taiwan. Int. J. Geriatr. Psychiatry 20, 635-644.

Cobb, S., 1976. Social support as a moderator of life stress. Psychosom. Med. 38, 300-314.

Cohen, S., Syme, S.L., 1985. Issues in the study and application of social support. In Cohen, S., Syme, S.L. (Eds.), Social Support and Health. San Francisco: Academic Press.

Collins, A.L., Goldman, N., Rodriguez, G., 2008. Is Positive Well-Being Protective of Mobility Limitations Among Older Adults? J. Gerontol. B: Psychol. Sci. Soc. Sci. 63 , P321-P327.

Council for Economic Planning and Development. 2008. Population Projections for Taiwan Areas: 2008-2056. Taipei: Executive Yuan.

Cuijpers, P., Smit, F., 2002. Excess mortality in depression: a meta-analysis of community studies. J. Affect. Disord. 72, 227-236.

Fiske, A., Gatz, M., Pedersen, N.L., 2003. Depressive Symptoms and Aging: The Effects of Illness and Non-Health-Related Events. J. Gerontol. B: Psychol. Sci. Soc. Sci. 58 , P320-P328.

Fiske, A., Wetherell, J.L., Gatz, M., 2009. Depression in Older Adults. Annu. Rev. Clin. Psychol. 5, 363-389.

Garnefski, N., Kraaij, V., 2006. Relationships between cognitive emotion regulation strategies and depressive symptoms: A comparative study of five specific samples. Pers. Individ. Dif. 40, 1659-1669.

Glei, D.A., Landau, D.A., Goldman, N., Chuang, Y.-L., Rodriguez, G., Weinstein, M., 2005. Participating in social activities helps preserve cognitive function: an analysis of a longitudinal, population-based study of the elderly. Int. J. Epidemiol. 34, 864-871.

Hybels, C.F., Blazer, D.G., Pieper, C.F., 2001. Toward a threshold for subthreshold depression: An analysis of correlates of depression by severity of symptoms using data from an elderly community sample. Gerontologist 41, 357-365.

Irwin, M., Artin, K.H., Oxman, M.N., 1999. Screening for depression in the older adult: Criterion validity of the 10-Item Center for Epidemiological Studies Depression Scale (CES-D). Arch. Intern. Med. 159, 1701-1704.

Katz, S., Gotf, A.B., Moskowitz, R.W., Jackson, B.A., Jaffe, M.W., 1963. Studies of illness in the aged: The index of ADLs. J. Am. Med. Assoc. 185, 914-919.

Kendler, K.S., Gatz, M., Gardner, C.O., Pedersen, N.L., 2006. Personality and major depression: A Swedish longitudinal, population-based twin study. Arch. Gen. Psychiatry 63, 1113-1120.

Kohout, F.J., Berkman, L.F., Evans, D.A., Cornoni-Huntley, J., 1993. Two shorter forms of the CES-D depression symptoms index. J. Aging Health 5, 179-193.

Krause, N., Liang, J., 1992. Cross-cultural variations in depressive symptoms in later life. Int. Psychogeriatr. 4, 185-202.

Krause, N., Liang, J., 1993. Stress, social support, and psychological distress among the Chinese elderly. J. Gerontol. 48, 282-291.

Krause, N., Markides, K., 1990. Measuring social support among older adults. Int. J Aging Hum. Dev. 30, 37-53.

Lawton, M.P., Brody, E.M., 1969. Assessment of older people: self-maintaining and instrumental activities of daily living. Gerontologist. 9, 179-186.

McCallum, J., Mackinnon, A., Simons, L., Simons, J., 1995. Measurement properties of the Center for Epidemiological Studies Depression Scale: an Australian community study of aged persons. J. Gerontol. B: Psychol. Sci. Soc. Sci. 50, S182-S189.

Meléndez, J.C., Tomás, J.M., Amparo Oliver, E.N., 2009. Psychological and physical dimensions explaining life satisfaction among the elderly: A structural model examination. Arch. Gerontol. Geriatr. 48, 291-295.

Mojtabai, R., Olfson, M., 2004. Major depression in community-dwelling middleaged and older adults: prevalence and 2- and 4-year follow-up symptoms. Psychol. Med. 34, 623-634.

Nolen-Hoeksema, S., Ahrens, C., 2002. Age Differences and Similarities in the Correlates of Depressive Symptoms. Psychol. Aging. 17, 116-124.

Ofstedal, M., Zimmer, Z., Lin, H., 1999. A comparison of correlates of cognitive functioning in older persons in Taiwan and the United States. J. Gerontol. B: Psychol. Sci. Soc. Sci. 54, S291-S301.

Radloff, LS., 1977. The CES-D Scale: A Self-report Depression Scale for Research in the General Population. Appl. Psychol. Meas. 1, 385-401.

Seplaki, C.L., Weinstein, N.G., Lin, Y.-H., 2006. Before and after the 1999 Chi-Chi earthquake: Traumatic events and depressive symptoms in an older population. Soc. Sci. Med. 62, 3121-3132.

Shrout, P.E., Yager, T.J., 1989. Reliability and validity of screening scales: Effect of reducing scale length. J. Clin. Epidemiol. 42, 69-78.

Wu, S.C., Chang, M.C., 1997. Health Care for the Elderly in Taiwan: A Fact Book, 19931994. Taiwan Provincial Institute of Family Planning. Taipei.

Zimmer, Z., Martin, L.G., Lin, H.-S., 2005. Determinants of old-age mortality in Taiwan. Soc. Sci. Med. 60, 457-470. 